$$
\zeta=
$$




\section{Una evolución en el concepto de alteridad: Levinas-Leopold}

\section{Introducción}

En el siguiente ensayo se reflexiona en torno a la propuesta de Emmanuel Levinas y su concepción de ética de la alteridad como un puente para enlazar con La ética de la Tierra, planteada por Aldo Leopold y así evolucionar el objeto de la ética de una alteridad que se refiere "al otro" para referirse a "lo otro" y poder hacer de los seres no humanos un objeto de obligaciones morales.

La circunstancia actual del hombre exige una reflexión especial que ayude a mediar las relaciones entre el hombre y los seres no humanos. De esta forma, se intentará un planteamiento que sustente la posibilidad de formular una ética que tenga como objeto lo otro y nos ayude a "humanizar" las relaciones que establecemos con la Tierra.

El ensayo sugiere la necesidad de una reflexión especial en torno a la posibilidad de una evolución en los planteamientos éticos respecto al concepto de alteridad que propone Emmanuel Levinas, y establece un puente con la propuesta de Aldo Leopold en su texto La ética de la Tierra.

\section{La visión de Levinas respecto del otro}

Un planteamiento que responde a la necesidad de modificar nuestra concepción de que el objeto de la ética es el hombre únicamente, dirigido a la alteridad, pero entendida como una alteridad "de lo otro" más que "del otro". De esta forma, tendemos a superar el individualismo y el especismo que han prevalecido desde hace tiempo y, por tanto, alejarnos del antropocentrismo (que aún prevalece en algunas posturas) para dar paso a un biocentrismo, que nos disponga a vernos como miembros de una comunidad biótica. 
Señala Levinas: “Soy totalmente solo; así, pues, el ser en mí, el hecho de que existo, mi existir, es lo que constituye el elemento absolutamente intransitivo, algo sin intencionalidad ni relación. Todo se puede intercambiar entre los seres, salvo el existir" ${ }^{1}$.

Por lo anteriormente señalado se destaca en el presente texto la propuesta de Emmanuel Levinas, filósofo judío contemporáneo que tuvo como maestros a Heidegger y Husserl y que, por un tiempo, se sumó al pensamiento fenomenológico propuesto por dichos filósofos; pensador judio, quien también sufrió en carne propia la experiencia de vivir en un campo de concentración nazi y perder a casi toda su familia en los campos de exterminio.

Hago alusión a sus orígenes porque, sin duda, la síntesis de todas esas características: su pasado judío, su adhesión a la fenomenología de Heidegger y Husserl, y su trágica vivencia de la Segunda Guerra Mundial dan como resultado su propuesta filosófica en torno a la ética: la ética de la alteridad.

Para explicar la ética de la alteridad propuesta por Levinas, recurro a una conferencia impartida por el filósofo de Kaunas titulada "Morir por...", en ella Levinas afirma la existencia del "eco de una crisis" ${ }^{2}$, dicha afirmación supone el inicio de dos rupturas, o mejor, una ruptura en dos frentes.

Por un lado, sucede una ruptura a nivel personal con su mentor, figura grandemente admirada por Levinas: Heidegger; debido principalmente a que Heidegger se suma a las posturas del Nacional Socialismo, lo que para Levinas supone una contradicción porque no logra entender cómo un hombre con tal capacidad intelectual comulgue con una doctrina de terror y muerte.

Sin embargo, lo que más nos interesa en relación con la filosofía (en particular con la ética) es que sucede una ruptura en un nivel superior, a nivel filosófico. Levinas es el profeta de esa ruptura: la ruptura del ser como "Da-sein", como base del pensar y de la existencia, como ser-propio, para develar a un ser en y para el otro como lo vislumbra Levinas, un ser que toma consciencia -que no es indiferente- de la existencia del otro y que sólo por la existencia del otro da cuenta de la existencia propia. Es la ruptura con el individualismo y con el logos -la razón- como base de la existencia del hombre.

1 Levinas, Emmanuel, Ética e infinito, Madrid, A. Machado libros, 2000, pp. $53-54$.

2 Levinas, Emmanuel, Morir por ... Archivos de filosofía, 8, 2014, p. 137. 
Levinas construye una relación yo-otro que permite realizar una descentralización de la conciencia del yo para abarcar ahora a la alteridad. Esta nueva relación supone la preocupación por el otro y la ruptura con la hegemonía del individualismo que ha gobernado el pensamiento occidental. De esa ruptura deriva la importancia de la propuesta filosófica de Levinas, pues se abre a la posibilidad de una ética para el otro. Ya no es más una ética del hombre solo.

La ética de la alteridad supone una preocupación por el otro que sea capaz de mantener la alteridad sin introducirla o inclusive reducirla a el mismo. El otro no es "un espejo en el que se proyectaría y objetivaría mi propia imagen" ${ }^{3}$. El otro es la fuente de una alteridad que me refiere la idea de infinitud (porque me desborda, me excede) y que socialmente me hace responsable del otro, pero superando la idea totalizante del otro en mí. Levinas aspira a una comprensión del "ser-en-el-mundo" que se realiza en un "ser-en-el-otro"

Para explicar la alteridad, Levinas ocupa el concepto de rostro, pues es cuando nos enfrentamos al rostro del otro que nos percatamos de esa alteridad que no significa una extensión de nosotros mismos, de el mismo; sino un otro que nos enfrenta y nos solicita que nos responsabilicemos de él.

Los seres no humanos que habitan la Tierra también tienen un rostro, un rostro no humano, un rostro que podemos pasar por alto. Sin embargo, si ponemos atención y lo enfrentamos, como enfrentamos el rostro del otro, también nos muestra su sufrimiento y su degradación: bosques y selvas devastadas, aire y agua contaminados, especies amenazadas o extintas.

Justamente bajo los imperativos de la ética de la alteridad y el hacernos conscientes de que existimos en un espacio habitado con los otros es que se propone trascender el concepto de alteridad y ahora, bajo las circunstancias que enfrenta el hombre, pasar de una alteridad entendida como "el otro" a una alteridad entendida como "lo otro". Se propone como objeto de la ética justamente lo otro, es decir, lo que cohabita y coexiste con nosotros en este espacio llamado Tierra.

El mundo es el espacio en el que se concreta el ser, es el espacio habitado por todos, el espacio donde"los unos son con los otros

3 Levinas, Emmanuel, Totalidad e infinito, Trad. de Daniel E. Guillot, Salamanca, Sígueme, 2002, p. 37.

4 Levinas, 2014, p. 139. 
y para los otros" ${ }^{15}$. Levinas afirma que si se continúa con el reinado del "Uno, Señor de todo el mundo"6, confundido con una forma impersonal del ser, ese Uno regirá el ethos del hombre.

\section{Leopold y la ética de la tierra}

Y es que, como asegura Aldo Leopold en La ética de la Tierra,"hasta ahora no hay una ética que se ocupe de la relación del hombre con la Tierra y con los animales y las plantas que crecen sobre ella"7. Pues la tierra, las plantas, los animales y todos los elementos no humanos siguen siendo objeto de pertenencia y propiedad.

Quizás podría pensarse que la carencia de inteligencia, creatividad o algunas otras características humanas en seres no humanos hace innecesario el planteamiento de una ética de lo otro. Sin embargo, la necesidad de una ética está implicada en las relaciones que se crean entre los hombres, entre las sociedades, entre las culturas y entre los pueblos. Luego entonces, cabe mencionar que entre el hombre y los seres no humanos también existen relaciones. Todos estamos intrincados, conectados, somos parte de una simbiosis.

Aldo Leopold advierte al respecto:

Todas las éticas que han evolucionado hasta este momento descansan sobre una sola premisa: que el individuo es un miembro de una comunidad cuyas partes son interdependientes. Sus instintos lo incitan a competir por su lugar en esa comunidad, pero su ética lo incita también a cooperar.

La ética de la Tierra simplemente amplía los límites de la comunidad para incluir suelos, aguas, plantas y animales, o colectivamente: la Tierra. ${ }^{8}$

Una ética de la Tierra nos vislumbra a humanos y no humanos como compañeros, como miembros de una comunidad, tal

5 Ibidem p. 144.

6 Idem.

7 Leopold, Aldo, La ética de la tierra, Revista ambiente y desarrollo, 23(1), Santiago de Chile, 2007, p. 30.

8 Idem. 
cual lo expresa Leopold, porque existimos en el mismo lugar y somos parte de una simbiosis.

La postura ética de una alteridad que conlleve a lo otro no precisamente nos niega el uso de cosas como el agua, la tierra, las plantas y los animales, pues muchas de ellas nos son absolutamente necesarias para subsistir.

Lo que nos solicita es dejar de considerarlos únicamente como recursos y al mismo tiempo entender su existencia tan sólo con base en los beneficios que nos aportan, como cosas que sólo existen para ser utilizadas por el hombre. En cambio, lo que nos solicita es abrirnos a la conciencia de que esos objetos no humanos tienen el mismo derecho a la existencia que nosotros, los humanos. Aldo Leopold lo expresa de la siguiente forma: "Una ética de la Tierra no puede, por supuesto, evitar la alteración, el manejo y el uso de esos 'recursos', pero sí afirma su derecho a su continua existencia $y$, por lo menos en ciertos lugares, a que su existencia continúe en un estado natural".

Esa preocupación por lo otro nos lleva a un tema actualmente en boga, pero por el que se hace poco: la conservación. ¿`Por qué su importancia?: porque, como expresa Aldo Leopold, "la conservación es un estado de armonía entre los hombres y la Tierra" Pero hablar de conservación implica hablar de responsabilidad y sacrificio. El ser humano debe comprometerse con lo otro y, por lo tanto, responsabilizarse de ello, tal como Levinas supone que debe hacerlo con el otro, con la alteridad. Ese responsabilizarse por lo otro implica también un sacrificio, el sacrificio del yo, o de el mismo, según la terminología de Levinas.

Así aparece la necesidad de una ética de lo otro, una ética que contemple la existencia de los no humanos y los proteja de nuestro uso indiferente, de nuestro uso abusivo casi siempre controlado por el interés económico. Una ética que nos ayude a ser conscientes del valor que los seres no humanos tienen en sí mismos y no un valor sólo referido a cuestiones económicas o de utilidad.

Se trata del valor de su existencia, ya no mediada por el logos o la razón, sino bajo la consideración de que los hombres no somos los únicos que habitamos este espacio llamado Tierra y de que

9 Leopold, Aldo, op. cit., 2007.

10 Idem. 
todos (humanos y no humanos) somos parte de una comunidad biótica, por lo que todos tenemos derecho a la existencia.

Aldo Leopold clarifica que "nunca se ha logrado un cambio importante en la ética sin un cambio interno en nuestras prioridades intelectuales, lealtades, afectos y convicciones" ${ }^{11}$. La importancia de mostrar el cambio de objeto en la ética tomando como puente la propuesta de Levinas radica justo en la necesidad de una ética de la Tierra, una ética que contemple a todos los seres que la habitamos y que contribuya a ese cambio interno en las prioridades, del que habla Aldo Leopold.

Leopold (2007) subraya: "Sólo podemos actuar éticamente en relación con aquello que podemos ver, sentir, comprender, amar o 'de algún modo' tener fe"12. Por ello, para justificar la ética de la alteridad, Levinas utiliza al rostro.

En la ética de Emmanuel Levinas el rostro es aquello que nos enfrenta y nos hace conscientes de la infinitud del otro, es decir, nos clarifica que no podemos comprenderlo totalmente porque no es una prolongación del mismo (del yo), pero nos solicita protección, nos obliga a responsabilizarnos del otro. La imagen que, según Aldo Leopold, debemos usar para responsabilizarnos de lo otro es la de la pirámide biótica.

La imagen de pirámide biótica implica una difusión de energía a través del servicio que se prestan unas especies a otras. Aldo Leopold desarrolla una explicación en su texto La ética de la Tierra. Nos habla de una pirámide, en cuya base se encuentra el suelo, la tierra, después continúan las plantas, que absorben su energía del sol. Posteriormente, sobre las plantas está una capa de insectos, le sigue una capa de pájaros y roedores, en una capa intermedia se halla el hombre junto con los animales omnívoros y, por último, la última capa es ocupada por los carnívoros ${ }^{13}$ (Leopold, 2007).

La pirámide que describimos está diferenciada entre niveles por el alimento y los servicios que prestan las capas inferiores a las superiores. De modo que, para dar servicio al nivel más alto (el de los carnívoros) se requieren los servicios de muchas especies. No abundaré en las explicaciones que realiza Aldo Leopold acerca del funcionamiento de dicha pirámide o acerca de cómo el hombre ha

11 Idem.

12 Idem.

13 Cfr. Leopold, Aldo. 
alterado el circuito de energía de la pirámide, pues él lo hace de manera magistral y no corresponde al propósito del ensayo. Sin embargo, retomaré dos puntos que me parecen vitales.

El primero es que entre esa pirámide se realizan diversos intercambios de servicios y competencias a los que nosotros designamos como cadena alimenticia y Leopold nos instruye muy bien en que no es una única cadena, como lo podríamos anticipar, sino una gran cantidad de cadenas alimenticias que forman un entramado complejo. Leopold (2007) agrega que "su funcionamiento depende de la cooperación y la competencia entre sus diversas partes"14. Inclusive, aclara que la pirámide no funciona únicamente hacia arriba, sino que es un circuito abierto que a través de la muerte reintegra la energía al suelo, al aire y al agua (Leopold, 2007 ${ }^{15}$.

La segunda consideración es el término servicio, al que le doy una importancia fundamental, ya que únicamente en la comprensión de que entre seres nos brindamos servicios es que podemos admitir la importancia de una ética de la Tierra.

Si ya hablamos de importancia ahora hablemos de necesidad. ¿Por qué es necesaria una ética de la Tierra? Aldo Leopold nos responde con el término salud. Una ética de la Tierra nos lleva a una consideración de la "responsabilidad individual por la salud de la Tierra"16 Leopold, 2007, entendiendo por salud la "capacidad de la Tierra para autorregenerarse"17. Leopold, 2007

¿Por qué es importante la Tierra y lo que la habita, tanto como el hombre? Porque el hombre es miembro de esa comunidad biótica, porque formamos parte de un entramado de relaciones bióticas de las cuales ni aun con el peso de la razón podemos escapar o estaríamos atentando contra nuestra propia existencia.

La consideración de la ética con un objeto más amplio que el hombre implica necesariamente una relación de reconocimiento, amor, respeto y admiración con lo otro (con lo no humano). Tal como una ética de la alteridad supone una relación de amor con el otro.

Si vamos un poco más lejos, esa ética de lo otro ayuda a superar el antropocentrismo, para incluirse en un biocentrismo, que

14 Idem.

15 Cfr. Idem.

16 Idem.

17 Idem. 
implicaría tener ciertas obligaciones morales con los seres no humanos.

Rodrigo Ocampo, en su artículo "Obligaciones morales con seres no humanos", realiza un recorrido por diversas posturas éticas para concluir que las obligaciones que tenemos para con los animales y la naturaleza devienen de la interacción social; al respecto expone: "Siempre que participan en nuestras interacciones sociales, los seres vivos nos salen al encuentro en el rol del alter ego como seres que se encuentran frente a nosotros, están necesitados de respeto y con ello fundan una expectativa de que defendamos fiduciariamente sus derechos" 18 .

Esta afirmación nos ayuda a constatar el supuesto de que el encuentro con la alteridad, ya sea con el otro como lo plantea Levinas, o bien, con lo otro, como se propone en el presente ensayo, nos compromete a tomar consciencia de esa alteridad $y$, por lo tanto, a cuidarla, respetarla, a ver por lo otro y por su derecho a la existencia.

Lo que nos puede ayudar a construir esta reflexión ética es entender que existe una relación entre la comunidad ecológica, o bien, la comunidad natural que habita la Tierra, de la que formamos parte y que nos interpela atender no únicamente a nuestros intereses humanos (económicos, políticos, legales) sino los intereses de toda la comunidad.

\section{Conclusión}

La preocupación de Levinas por alejar al hombre del individualismo y que voltee a ver al otro se hace imprescindible en una época histórica como la que él vivió y enfrentó durante la Segunda Guerra Mundial, época en la que ya existían posturas filosóficas en torno al respeto a la vida y a la dignidad del hombre, pero en la cual se hace presente (en sus circunstancias) dudar acerca de esos sistemas de pensamiento y se distinguen sus carencias para después romper con ellos y proponer dirigir la mirada hacia la alteridad.

De la misma forma, estamos hoy ante circunstancias diferentes: el hombre se enfrenta a un ecosistema cada vez más deteriorado, más desgastado y vislumbramos muchos problemas éticos

18 Ocampo, G. Rodrigo, J. Obligaciones morales con seres no bumanos, Revista CS, 13, enero-junio, 2014, Cali, Colombia, pp. 195-196. 
y filosóficos a la luz de un sistema de pensamiento que -desde hace siglos- se sigue centrando en el hombre, en la especie humana como superior a lo otro.

Enlazar la ética propuesta por Levinas con la reflexión acerca de La ética de la Tierra que propone Leopold nos ayuda a mediar las relaciones entre el hombre y los seres no humanos bajo la comprensión de que lo que habita en la Tierra tiene un rostro, que aunque puede parecer imperceptible también nos muestra su sufrimiento y nos interpela para hacernos responsables de él.

Nos ayuda también a comprender que tanto los seres humanos como los seres no humanos formamos parte de un entramado complejo llamado comunidad biótica, y que por tanto nos necesitamos unos a otros para brindarnos servicios y coexistir.

Por último, el puente entre la ética de la alteridad y la ética de la Tierra nos brinda la oportunidad de superar el antropocentrismo y colocarnos en un biocentrismo que nos ayude a establecer relaciones de respeto y a garantizar el derecho a la existencia de seres humanos y seres no humanos.

La propuesta del presente ensayo es un intento mínimo de mirar hacia esos otros problemas éticos que también nos urgen a cuestionarnos y plantear una posibilidad de respuesta desde otras perspectivas. Aun cuando la verdad absoluta e inmutable esté muy lejos de nuestro alcance. 